\title{
David Oliver: Is hospital avoidance an elusive holy grail?
}

\section{David Oliver consultant in geriatrics and acute general medicine}

Berkshire

The first weeks of 2019 saw NHS England publish the long term plan for the NHS, ${ }^{1}$ the new five year GP contract framework, ${ }^{2}$ and the plan for universal personalised care. ${ }^{3}$ They all include an overarching idea that we should be trying to prevent people attending or being admitted to hospital.

The GP contract and the promised additional $£ 4$.5bn for primary and community services are linked to a requirement that the new GP networks will be financially incentivised to cut emergency department attendances and hospital admissions. The NHS plan aims to reduce acute hospital bed use through a national roll-out of the NHS 111 urgent advice line and web service, GP led urgent treatment centres with diagnostics, community multidisciplinary rapid response teams, and enhanced support for care home residents.

We'd probably all agree that, wherever possible, people-including those with long term conditions or frailty - would prefer to avoid crises in the first place, have more responsive out-of-hospital services when they do get ill, and spend less time in hospital when they're admitted. And we've been seeking the holy grail of avoiding admissions and attendances for many years in the NHS, with the notion that reducing or managing demand would improve care and save money.

It's easy to see the drivers for these ambitions. Over the past three decades NHS bed capacity has been reduced continually, while demand has risen inexorably. ${ }^{45}$ England has just about the lowest number of hospital beds per head of population of all countries in the Organisation for Economic Cooperation and Development. ${ }^{6}$ Access to intermediate care services outside hospital has not kept pace and is now worsening, ${ }^{7}$ social care has experienced sustained cuts, ${ }^{8}$ and numbers of GPs, community nurses, and health visitors have all fallen despite rising demands on primary care. ${ }^{9-11}$

Perhaps we've placed too much emphasis on hospital avoidance and too much hope on what it might deliver

Hospital attendance and admission rates continue to rise-and more quickly than the percentage of admissions for potentially preventable ambulatory or primary care sensitive conditions. ${ }^{12}$ Performance against the four hour wait time target has worsened in recent years and reached a record low. Delayed transfer bed days hit a record high in 2016 and have fallen only slightly since. Perhaps we've placed too much emphasis on hospital avoidance and too much hope on what it might deliver.

With the political and reputational damage that comes from a high profile part of our system publicly cracking under pressure, this is no surprise. Initiatives to reduce demand and activity in urgent care go back through several parliaments. Despite local pockets of success among some patient groups they haven't delivered at scale across regions or nations, and expectations have always been unrealistic.

Next week I'll discuss how we might rebalance the narrative and temper the ambitions.

1 NHS England. NHS long term plan. 7 Jan 2019. https://www.england.nhs.uk/long-termplan/.

2 NHS England. A five-year framework for GP contract reform to implement The NHS long term plan. 31 Jan 2019. https://www.england.nhs.uk/publication/gp-contract-five-yearframework/.

3 NHS England. Universal personalised care: implementing the comprehensive model. 31 Jan 2019. https://www.england.nhs.uk/publication/universal-personalised-careimplementing-the-comprehensive-model/

4 Appleby J. The hospital bed: on its way out?BMJ 2013;346:f1563. 10.1136/bmj.f1563 23482956

5 Royal College of Physicians. Hospitals on the edge? The time for action. https://www. rcplondon.ac.uk/guidelines-policy/hospitals-edge-time-action.

6 King's Fund. NHS hospital bed numbers: past, present, future. 29 Sep 2017. https://www. King's Fund. NHS hospital bed numbers: past, present, fut
kingsfund.org.uk/publications/nhs-hospital-bed-numbers.

7 NHS Benchmarking Network. National Audit of Intermediate Care (NAIC) summary report 2017 for England. Nov 2017. https://s3.eu-west-2.amazonaws.com/nhsbn-static/NAIC+( Providers)/2017/NAIC+England+Summary+Report+-+upload+2.pdf.

8 King's Fund. The NHS at 70: What's the problem with social care, and why do we need to do better? 26 Jun 2018. https://www.kingsfund.org.uk/publications/nhs-70-whats-theproblem-with-social-care.

9 Bostock N. Full-time GP workforce drops by more than 500 in three months. GP 2018. https://www.gponline.com/full-time-gp-workforce-drops-500-three-months/article/1491044

10 Rai-Roche S. Drop of nearly $50 \%$ in the number of district nurses since 2010. Independent Nurse 22 Nov 2017. http://www.independentnurse.co.uk/news/drop-of-nearly-50-in-thenumber-of-district-nurses-since-2010/165084.

11 lacobucci G. Ongoing GP shortage puts NHS long term plan at risk, warn experts. BMJ 2019;364:1686.

12 Nuffield Trust. Potentially preventable emergency hospital admissions. 10 Jan 2019. https: //www.nuffieldtrust.org.uk/resource/potentially-preventable-emergency-hospital-admissions.

Competing interests: see www.bmj.com/about-bmj/freelance-contributors. 
Published by the BMJ Publishing Group Limited. For permission to use (where not already granted under a licence) please go to http://group.bmj.com/group/rights-licensing/ permissions 